\title{
Pattern of use of anti-hypertensive drugs amongst hypertensive patients in a tertiary care hospital: a cross sectional, observational study
}

\author{
Sharmin Khan, Ram N. Maiti*, Sekhar Mandal
}

Department of Pharmacology, Midnapore Medical College, West Midnapore, West Bengal, India

Received: 05 September 2019

Revised: 31 October 2019

Accepted: 28 November 2019

\section{*Correspondence:}

Dr. Ram N. Maiti,

Email: ram.narayan.maiti@gmail.com

Copyright: ( $)$ the author(s), publisher and licensee Medip Academy. This is an open-access article distributed under the terms of the Creative Commons Attribution Non-Commercial License, which permits unrestricted non-commercial use, distribution, and reproduction in any medium, provided the original work is properly cited.

\begin{abstract}
Background: Hypertension is one of the primary modifiable risk factors for cardiac and renal diseases and is the single most important risk factor for stroke. Despite different guidelines for management of hypertension like Joint National Committee, British Hypertension Society, National Institute for Health and Care Excellence; there are still the clouds of controversy. The objective of the study was to evaluate the prescribing pattern of antihypertensive drugs among the patients attending medicine outpatient department of a tertiary care teaching hospital

Methods: A cross-sectional, observational study was conducted in our hospital over a period of six months. Relevant information was collected from medical records of 209 hypertensive patients fulfilling inclusion criteria. The collected data were sorted and analyzed.

Results: Out of 209 patients, maximum were of age group of 45-65 years (55.02\%). 115 (55.02\%) were male and 94 $(44.97 \%)$ were female. Diabetes mellitus $(24.4 \%)$ was the most common associated disease with hypertension. Most of the patients had received single antihypertensive drugs (49.28\%). Among the monotherapy category calcium channel blocker $(82.78 \%)$ was the most commonly prescribed antihypertensive drug class followed by angiotensin receptor blocker $(36.36 \%)$. Amlodipine $(81.82 \%)$ was the most common among calcium channel blockers. The most frequent fixed drug combination prescribed consisted of amlodipine and atenolol. Most of the drugs were prescribed in generic name $(90.9 \%)$.
\end{abstract}

Conclusions: The treatment pattern, in general, conformed to standard treatment guidelines.

Keywords: Hypertension, Amlodipine, Generic

\section{INTRODUCTION}

Hypertension is one of the primary modifiable risk factors for cardiac and renal diseases and is the single most important risk factor for stroke. ${ }^{1}$ Hypertension has been described as the "largest epidemic ever known to mankind" and it is beyond doubt that hypertension is a serious threat to public health worldwide and most important non communicable disease leading to mortality and morbidity. ${ }^{2}$ During the last four decades, prevalence of hypertension raised from 594 million in 1975 to 1.13 billion in $2015 .^{3}$ Not only that, highest blood pressure levels were shown in South Asia, Central and Eastern Europe areas. As per the study of 2015, South Asia accommodates about 258 million patients of which India shares 199 million. Different meta-analysis showed that usual blood pressure is strongly and directly related to vascular mortality amongst middle and old aged population. ${ }^{4}$ Every $20 / 10 \mathrm{~mm} \mathrm{Hg}$ rise in BP results in two fold increased risk of cardio vascular mortality and morbidity above the BP threshold of $115 / 75 \mathrm{~mm} \mathrm{Hg}{ }^{5}$ Hence reduction in $\mathrm{BP}$ reduces the risk of death due to stroke and cardiovascular disease (CVD) death. ${ }^{6}$ 
Despite different guidelines for management of hypertension like Joint National Committee, British Hypertension Society, National Institute for Health and Care Excellence; there are still the clouds of controversy. However, the common link of all these guidelines is that definition of hypertension is $\geq 140 / 90 \mathrm{~mm} \mathrm{Hg}$ and $>130 / 80 \mathrm{~mm} \mathrm{Hg}$ even in presence of diabetes mellitus, chronic kidney disease (CKD), heart failure. The basics of hypertension management include Life style modification and pharmacotherapy are common mission of all guidelines is to reduce the global burden of CVD. ${ }^{6}$

As the treatment of hypertension is lifelong and different classes of drugs are available, so aim of therapy should point ease of administration of drugs and also cost effectiveness for better therapeutic outcome vis a vis to reduce the pill burden and bill burden.

The present prescription monitoring study for antihypertensive drugs was undertaken with the purpose to investigate the use of antihypertensive drugs in hypertensive patients in order to establish the current trend of pattern of prescribing of antihypertensive drug; and to identify whether such pattern of prescription is appropriate and accordance with international guidelines for pharmacotherapy of hypertension with the emphasis on generic prescription to achieve the therapeutic goal of blood pressure control.

The objective of this study was to evaluate the drug prescribing pattern among hypertensive patients attending medicine OPD of our tertiary care teaching hospital (using WHO drug use indicator), to assess the number of anti-hypertensive drugs used per prescription, the rationality of drug prescription and the average cost per prescription.

\section{METHODS}

A cross-sectional, observational study was conducted by Department of Pharmacology in association with Department of Medicine in Midnapore Medical College and Hospital, Paschim Midnapore. The study was conducted over a period of 6 months after approval from Institutional Ethics Committee (Approval letter No. MMC/IEC-2017/2698, December 22, 2017).The patients included were those who were registered in the medicine OPD during the period 22 January 2018 to 22 July 2018. The diagnosis and line of treatment to be given was decided by the physician in charge of the Department of Medicine. No additional drugs or investigations were advised by us during the study period. Data of patients matching inclusion criteria were recorded after getting informed consent. Identity of patient was kept confidential.

The following data were collected: age, sex, registration number, height, weight, diagnosis, duration of illness. Each drug prescribed to the patient was noted as follows: brand/generic name, indication, route of administration, dose and frequency of administration and date of starting the drug.

\section{Inclusion criteria}

All patients >30 yrs, patients with diagnosis of hypertension, able to communicate, treatment naive patients were included in this study.

\section{Exclusion criteria}

Pregnancy induced hypertension example eclampsia/ preeclampsia; malignant hypertension; hypertensive emergency were excluded in this study.

Descriptive statistics like mean and percentages were used for the analysis for the interpretation of results. Statistical analysis was performed using SPSS version 21.

\section{RESULTS}

\section{Demographic details}

During the study period, a total of 209 hypertensive patients fulfilled the criteria for inclusion in the study analysis. Among them $115(55.02 \%)$ patients were male and $94(44.97 \%)$ were female. Male:female ratio was 1.223:1 (approx.) indicating that hypertension is slightly more prevalent in the male gender. The mean age of the study population was found to be 57.14 years with a standard deviation of 0.693 years (Table 1 ).

Table 1: Mean age, systolic, diastolic blood pressure of the subjects.

\begin{tabular}{|llll|}
\hline Variable & & Mean & +SD \\
\hline Age (in years) & & 57.14 & 0.693 \\
\hline $\begin{array}{l}\text { Systolic blood } \\
\text { pressure (mmHg) }\end{array}$ & Male & 142.26 & 17.71 \\
\cline { 2 - 4 } $\begin{array}{l}\text { Diastolic blood } \\
\text { pressure (mmHg) }\end{array}$ & Male & 143.85 & 18.74 \\
\cline { 2 - 4 } & Female & 88.48 & 11.33 \\
\hline
\end{tabular}

In this study, more than two-third $(70.2 \%)$ of the patients were illiterate. $64.3 \%$ of the patients were non-smokers and $35.7 \%$ of the patients had smoking history present. More than half $(64.7 \%)$ of the patients belonged to rural areas. Most of the respondents were engaged (68.4\%) in one of the other occupation.

Almost half of the patients were found to be obese (48.6\%) and $29.3 \%$ were overweight as per Asia Pacific perspective for Asians (WHO IOTF 2003).

The age distribution of hypertensive patient was 33 (15.8\%) below the age of 45 years, $115(55.02 \%)$ were between 45 and 65 years and $61(29.19 \%)$ were above 65 years (Figure 1). 


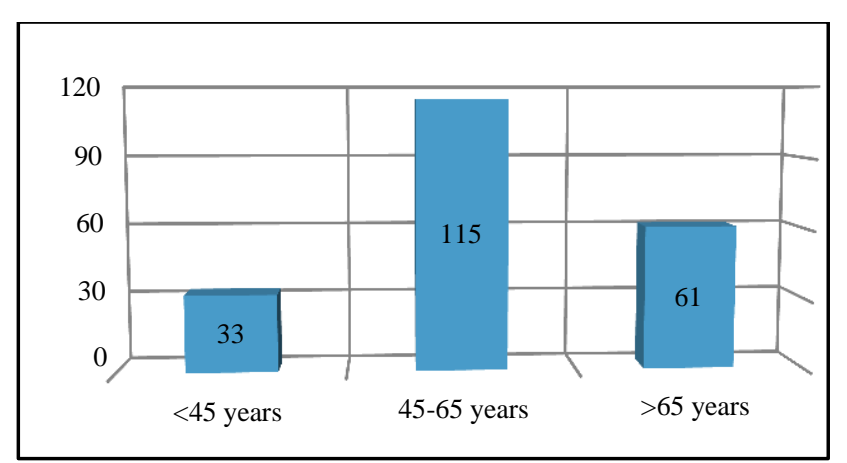

Figure 1: Age group distribution of patients.

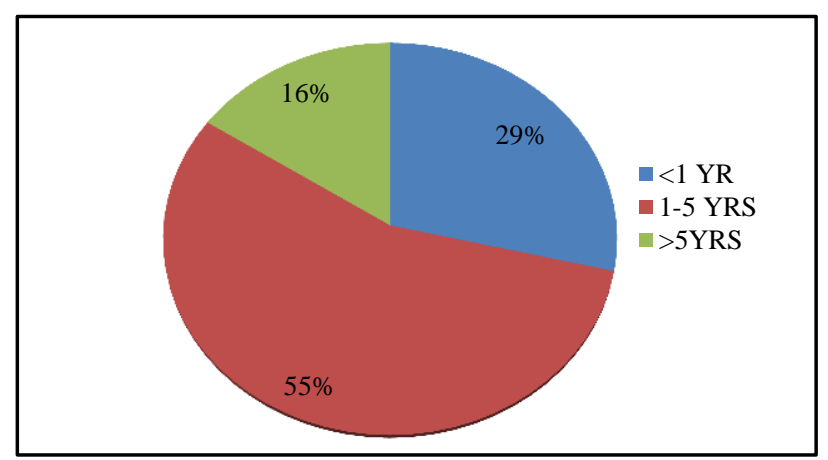

Figure 2: Distribution of study samples as per duration of hypertension.

In our study most of the patients were suffering from hypertension for a period of $1-5$ years $(56 \%)$ followed by $0-1$ year $(29 \%)$ and more than 5 years $(16 \%)$ duration (Figure 2).

\section{Comorbidities}

Total 134 patients $(74.0 \%)$ were suffering from only hypertension. Diabetes 51 (24.40\%) was the commonest comorbidity followed by dyslipidemia 27 (12.92\%), cerebrovascular disease 22 (10.53\%), thyroid disorders 10 $(4.78 \%)$, coronary artery diseases $9(4.30 \%)$ and others 13 $(6.22 \%)$ like neuropathy, COPD, seizure disorder, hyperuricemia etc (Table 2).

Table 2: Significant comorbidities.

\begin{tabular}{|lll|}
\hline Comorbidity & Number & Percentage (\%) \\
\hline Diabetes mellitus & 51 & 24.40 \\
\hline Dyslipidemia & 27 & 12.92 \\
\hline CVA & 22 & 10.53 \\
\hline Hypothyroidism & 10 & 4.78 \\
\hline CAD & 9 & 4.30 \\
\hline Others & 13 & 6.22 \\
\hline
\end{tabular}

\section{Pharmacotherapy}

For the purpose of analyzing the prescriptive patterns of antihypertensive drugs in the treatment of hypertension the pharmacotherapy was classified as monotherapy, dual therapy, triple therapy and four drug therapies, where single antihypertensive, two, three and four antihypertensives respectively were used for the treatment. Table 3 shows the number of patients who underwent treatment under different groups.

Table 3: Number of drugs prescribed.

\begin{tabular}{|lll|}
\hline No. of drugs & Number & Percentage $(\%)$ \\
\hline Single drug & 103 & 49.28 \\
\hline Two drugs & 100 & 47.84 \\
\hline Three drugs & 5 & 2.39 \\
\hline Four drugs & 1 & 0.48 \\
\hline
\end{tabular}

About half of the patients had received one antihypertensive drug $103(49.28 \%)$, followed by two 100 $(47.84 \%)$, three $5(2.39 \%)$ and four $1(0.48 \%)$ antihypertensive drugs. $49.28 \%$ of the patients were on mono therapy and $50.72 \%$ were on combination therapy.

\section{Pattern of drug use}

Calcium channel blockers (CCBs) was the most preferred anti-hypertensive drug class $173(82.78 \%)$ prescribed followed by angiotensin II receptor blockers (ARBs) 76 $(36.36 \%)$, diuretics $40(19.14 \%)$, Beta blockers 33 $(15.79 \%)$, and angiotensin-converting-enzyme inhibitors (ACEIs) $26(12.44 \%)$ in that order.

Table 4: Frequency of administration of individual drugs.

\begin{tabular}{|lll|}
\hline $\begin{array}{l}\text { Antihypertensive } \\
\text { group }\end{array}$ & Name of drug & $\begin{array}{l}\text { Number of } \\
\text { prescriptions }\end{array}$ \\
\hline $\begin{array}{l}\text { Calcium channel } \\
\text { blockers (173) }\end{array}$ & Amlodipine & 171 \\
\cline { 2 - 3 } ARB (76) & Cilnidipine & 2 \\
\hline \multirow{2}{*}{ Diuretics (40) } & Losartan & 50 \\
\cline { 2 - 3 } & $\begin{array}{l}\text { Telmisartan } \\
\text { Hydro- } \\
\text { chlorthiazide }\end{array}$ & 26 \\
\cline { 2 - 3 } Chlorthalidone & 14 \\
\hline $\begin{array}{l}\text { Beta blockers } \\
\text { (33) }\end{array}$ & Atenolol & 21 \\
\hline $\begin{array}{l}\text { Ace inhibitors } \\
\text { (26) }\end{array}$ & Metoprolol & 12 \\
\cline { 2 - 3 } & Enalapril & 13 \\
\hline
\end{tabular}

Amlodipine $171(81.82 \%)$ was the most commonly prescribed antihypertensive agent both as mono therapy and combination therapy followed by losartan 50 (23.92\%). The most prevalent combination of drug was a 2-drug therapy of CCBs and ARBs which was found to be $47(22.4 \%)$ followed by CCB and diuretics $17(8.13 \%)$. Among the three drug combinations, diuretics, ARB and $\mathrm{CCBs}$ comprised the most commonly prescribed combination $4(1.91 \%)$ (Table 4$)$.

\section{Other drugs co-prescribed}

Oral hypoglycemic drugs were prescribed very commonly as diabetes was the most frequent associated comorbidity 
in the study samples. Among them metformin was given in 51 patients $(34.80 \%)$. Glimepiride were given in 38 $(16 \%)$ cases. Gliptins were prescribed in 11 cases $(10.49 \%)$.

Anticoagulants were prescribed to 22 patients (10.53\%). Among them aspirin $75 \mathrm{mg}$ was given most commonly (15 cases) and clopidogrel $75 \mathrm{mg}$ was given only in 7 cases. HMG-Co A reductase inhibitors were given in 47 patients $(22.49 \%)$. Atorvastatin was given to 36 patients and rosuvastatin in 11 patients.

Antimicrobials were prescribed in 28 encounters only $(13.4 \%)$. Antibiotics were given to patients who had some infections e.g. urinary tract infection, respiratory tract infection, etc. Azithromycin (21.42\%) and levofloxacin $(17.6 \%)$ was used most commonly among antibiotics.

A total of 22 fixed dose combinations were prescribed of which amlodipine and atenolol was most commonly prescribed $(\mathrm{n}=12)$.

Table 5: Frequency of co-prescribed drugs.

\begin{tabular}{|lll|}
\hline Drugs & Number & Percentage (\%) \\
\hline Statins & 47 & 12.91 \\
\hline OHA & 100 & 47.84 \\
\hline Anti-coagulants & 22 & 10.53 \\
\hline L-thyroxine & 11 & 4.87 \\
\hline Others & 62 & 29.67 \\
\hline
\end{tabular}

\section{Key prescribing indicators}

Average number of drugs per prescription (encounter) was around 3.22 whereas, average number of antihypertensive drugs per prescription (encounter) was around $1.96 \pm 0.79$. $90.9 \%$ prescriptions were in generic name. $13.4 \%$ of encounters were with an antibiotic and $17.7 \%$ with injection. $42.31 \%$ of the drugs prescribed were from essential drugs list (NLEM 2011). Average drug cost per encounter 13.50 INR and average cost of anti-hypertensive/prescription/day- 5.5 \pm 0.79 INR.

\section{Patient care indicators}

Average consulting and dispensing time was 8.48 minutes and 1.26 minutes respectively.

$85 \%$ of drugs were actually dispensed. $69.06 \%$ of the patient's had knowledge of correct dosage.

\section{Facility indicators}

Copy of essential drug list or formulary was present. Availability of key drugs was $90 \%$.

\section{DISCUSSION}

Hypertension is a worldwide problem with an alarming increase in its prevalence. Appropriate antihypertensive drug therapy is important as any deviation from evidence based guidelines in hypertension treatment contributes to high economic burden to the population. ${ }^{8}$

This study is essentially an observational, cross-sectional study on the prescribing pattern of drugs for the treatment of hypertension carried out over a period of six months (January 22, 2018- July 22, 2018). A prescription-based survey is regarded as one of the most effective methods to assess and evaluate the prescribing attitude of physicians.

\section{Demographic characteristics}

In this study of 209 patients, $115(55.02 \%)$ were male and $94(44.97 \%)$ were female. A relative male preponderance was also observed in other studies. ${ }^{8,9}$ However, some studies have shown relatively higher incidence of hypertension in females than in males. ${ }^{10,11}$

Maximum patients belonged to age group of 45-65 years $115(55 \%)$, followed by $>65$ years $61(29.2 \%)$ and $<45$ years $33(15.8 \%)$. A study in India found most common age group 50-59 years (33.3\%) followed by 60-69 years and 40-49 years $(26.7 \%)$. ${ }^{11}$ Another study reported most common age group 60-69 years (34\%) followed by 70-79 years $(23 \%)$ and $40-49$ years $(22 \%){ }^{12}$ In current study, mean age of study subjects were $57.14 \pm 0.693$ years similar to that found in other study. ${ }^{13}$

In these patients, the duration of hypertension ranged from newly diagnosed hypertension up to 25 years, with a median duration of five years. In this study most of the patients were suffering from hypertension for a period of 0-6 months $(26.8 \%)$.

The mean systolic blood pressure $(\mathrm{mm} \mathrm{Hg})$ of the study population was found to be $146 \pm 19.318$, mean diastolic blood pressure $(\mathrm{mm} \mathrm{Hg})$ was $89.59 \pm 10.184$ and mean pulse pressure $(\mathrm{mm} \mathrm{Hg}$ ) was $54.77 \pm 18.450$.

\section{Co-morbid conditions}

Patients with chronic diseases like hypertension usually suffer from other associated conditions. In our study, majority of the patients were suffering from concurrent diabetes $(24.4 \%)$. Other commonly associated conditions were dyslipidemia (12.92\%), CVD (10.53\%), thyroid disorder $(4.78 \%)$, CAD $(4.3 \%)$ and others disease $(6.22 \%)$. Sakthi et al reported diabetes mellitus (35\%) as the most frequent co-morbidity followed by asthma (5\%) and ischemic heart disease $(1.6 \%) .{ }^{14}$

\section{Pattern of anti-hypertensive prescriptions}

In this study, all the prescription patterns of antihypertensive drugs prescribed conform to the oral route of administration. In general the prescription patterns reported so far, highlight the importance of monotherapy and combination therapy. 
Monotherapy implies the use of an individual drug selected from the respective generic group (eg. amlodipine from the group CCBs and losartan from the group ARB). Combination therapy means the use of two or more anti hypertensives at a time, chosen from appropriate different groups (eg. amlodipine as a CCB and telmisartan as an ARB).

The present study observed that multiple drug therapy 106 $(50.72 \%)$ was more common than single drug therapy 103 (49.28\%). Combination therapy seems to be a rational approach to reduce the cardiovascular mortality. ${ }^{15}$

The increasing use of combination therapy as compared to mono therapy in this study is similar with the JNC7 Report which states that most hypertensive patients with diabetes or renal disease will require two or more antihypertensive drugs to achieve the target blood pressure of <130/85 mm Hg. ${ }^{16}$

Since large number of patients were suffering from concomitant diabetes, coronary artery disease, and dyslipidemia, they are likely to have required multiple anti-hypertensives to achieve optimal blood pressure control and impede end organ damage.

In this study, the choice of amlodipine, losartan, hydrochlorthiazide, atenolol, and enalapril in preference to other drugs from the same respective groups is overwhelming and noteworthy. Thus the importance of amlodipine (a long acting CCB), losartan (an ARB), hydrochlorthiazide (a diuretic), atenolol (a cardioselective beta blocker), and enalapril (an ACEI) either individually and or in appropriately chosen combination is realised.

In our study, among the antihypertensive drug classes a long acting CCB was the most preferred anti hypertensive $173(82.78 \%)$ followed by an ARB 76 (36.36\%), a diuretic $40(19.14 \%)$, a beta blocker $33(15.79 \%)$ and an ACEI 26 (12.44\%) in that order.

A study reported ACEIs (47\%) were most commonly prescribed drug followed by CCBs (25.85\%), beta blockers $(12 \%)$, angiotensin receptor blockers $(10.8 \%)$ and diuretics $(3.7 \%){ }^{17}$

Other study reported calcium channel blockers (49\%) were the most commonly prescribed drugs followed by diuretics (43.5\%), angiotensin converting enzyme inhibitors $(29.5 \%)$ beta blockers $(29 \%)$, angiotensin receptor blockers $(21 \%)$, alpha adrenergic blockers $(2 \%)$ and central sympatholytics $(2 \%){ }^{12}$

This difference might be due to physician's choice with relation to the characteristics of patients, their concurrent illness, as well as the availability of medicines.

Among the individual antihypertensive drugs, amlodipine (CCB) was the most commonly prescribed drug 171
(81.82\%) followed by losartan (ARB) 50(23.92\%). Solanki et al reported enalapril (ACE inhibitor) as the most commonly prescribed drug $(79.66 \%)$ followed by atenolol (beta blocker) $(49.66 \%){ }^{18}$

CCBs, both as monotherapy and in combination, have been used most frequently. The share of the CCBs 173 $(81.82 \%)$ in terms of total number of drugs prescribed is more than twice as much as the second largest antihypertensive group of ARBs 76 (36.36\%). The use of amlodipine as an individual antihypertensive drug far exceeds the utilization of any other single agent. A similar pattern of $\mathrm{CCB}$ and amlodipine use has also been observed in some other studies. ${ }^{9,19,20}$ Advantages of amlodipine such as long half-life, sustained and consistent blood pressure control with once daily dosing, and improved compliance are factors that make it one of the novel antihypertensive agent and probably contribute to its predominant utilization. ${ }^{21}$

In this study, ARB was prescribed in $76(36.36 \%)$ cases while ACEI were prescribed in 26 (12.44\%) cases. This result is likely due to the fact that many physicians in our setting are getting more conversant with current trends in hypertension management and may also be due to the fact that these medications are getting more accessible and affordable for our patients. As ACEI have been found to be very useful in preventing cardiovascular events and target organ damage in patients with hypertension. They have been shown to control blood pressure and reverse proteinuria in both hypertensive-diabetic patients and chronic kidney disease and also found to reduce mortality in patients with hypertensive heart failure. ${ }^{22}$

The utilization of diuretics particularly that of the thiazides, was low $40(19.14 \%)$ as compared to the other antihypertensive drug groups. Such underutilization of thiazides has been observed across many studies despite being recommended as the first choice antihypertensive consequent to their ability to prevent major cardiovascular events and low cost. The relatively less frequent use of thiazides could be a result of concerns regarding adverse effects and poor market availability. ${ }^{23}$

The use of beta-blockers in $33(15.79 \%)$ cases is mainly due to the combination of beta-blockers like atenolol or metoprolol to ameliorate reflex tachycardia which is sometimes associated with CCBs.

Consideration of comorbid conditions seems to take precedence over other factors while selecting an appropriate antihypertensive similar to other study. ${ }^{23}$

A total of 22 fixed dose combinations were prescribed of which amlodipine and atenolol was most commonly prescribed $(n=12)$. Fixed dose combinations are seen to improve adherence to treatment with advantages in blood pressure control and adverse effects.

Average anti-hypertensive drugs/prescription was $1.96 \pm 0.79$ similar to other studies. ${ }^{24}$ 
The average number of drugs per encounter was 3.22 in our study with median 2 and range of 1 to 9 which is in proximity to $3.8 \pm 1.1$ drugs per prescription as reported earlier by Akici et al. ${ }^{25}$

90.9\% prescriptions were in generic name. Increasing generic prescribing would rationalise the use and reduce the cost of drugs. ${ }^{26}$

\section{LIMITATIONS}

- Cross-sectional study design.

- Uni-centric and data was collected only from the outpatient department thus not representative of prescription patterns across the state.

- Small sample size.

- Special groups like pregnant women, mentally challenged patients, drug addicts, patients with CKD, CLD were not included in the study.

Larger studies involving different age groups and large number of patients are required to implement these findings to general population of India.

\section{CONCLUSION}

Hypertension is one of the most important noncommunicable disease, throughout the globe with increasing prevalence, leading to morbidity and mortality like coronary artery disease, stroke, myocardial infarction. So strict control of blood pressure can reduce these cardiovascular events. There are plethora of guidelines and different class of drugs available to achieve the proper control of BP that is $<140 / 80$ without co-morbidities and $<130 / 80$ with co-morbidities like DM, CKD. As the treatment of hypertension is a lifelong measure, so judicious use of lifestyle modification and pharmacotherapy are very important to achieve the goal. The present study was undertaken to see the current drug utilisation of anti-hypertensive therapy within the acceptable guidelines. The result of the study showed that most commonly prescribed anti-hypertensive drugs are CCB (81.82\%), ARB (36.36\%), ACEI (12.44\%), diuretics (19.14\%), beta blockers (15.79\%) per prescription survey in our hospital. This selection of drugs may be due to availability of drugs, choice of treating physician, presence and absence of co-morbidities. Most of the prescriptions $(90.9 \%)$ were in generic name. There was no gender difference in selecting drugs in this study. Some prescriptions with fixed dose and multiple drugs were also found which included these current medications used. The survey of the prescriptions also showed rationality of the treatment as per guidelines. However, large study is required to substantiate this issue.

Funding: No funding sources Conflict of interest: None declared

Ethical approval: The study was approved by the Institutional Ethics Committee

\section{REFERENCES}

1. Andreadis EA. Hypertension and cardiovascular disease. Springer; 2016: 1-17.

2. High Blood Pressure: the largest epidemic known to mankind. Available at: www.irish.com. Accessed on 4 May 2017.

3. NCD Risk Factor collaboration (NCD-Rise). Lancet. 2017;386(10064):37-55.

4. Lewington S, Clarke R, Qizilbash N, Peto R, Collins $\mathrm{R}$; Prospective Studies Collaboration. Age-specific relevance of usual blood pressure to vascular mortality: a meta-analysis of individual data for one million adults in 61 prospective studies. Lancet. 2002;360(9349):1903-13.

5. New approaches to managing dyslipedemia: Risk Reduction Beyond LDL-C. Available at: http://www. medscape.org/viewarticle. Accessed on 4 May 2017.

6. Rosendorff C, Black HR, Cannon CP, Gersh BJ, Gore J, Izzo JL Jr, et al. Treatment of hypertension in the prevention and management of ischemic heart disease. Circulation. 2007;115:2761-88.

7. Mandal S, Maiti T, Das AK, Das A, Mandal A, Sarkar BS, et al. Drug utilization study in patients with type 2 diabetes mellitus attending diabetes clinic of a tertiary care hospital in rural Bengal. Int $\mathrm{J}$ Basic Clin Pharmacol. 2016;5(4):1647-54.

8. Rachana PR, Anuradha HV, Shivamurthy MC. Anti Hypertensive Prescribing Patterns and Cost Analysis for Primary Hypertension: A Retrospective Study. J Clin Diagn Res. 2014;8(9):19-22.

9. Xavier D, Noby M, Pradeep J, Pais P. Pattern of drug use in hypertension in a tertiary hospital: A cross sectional study in the in-patient wards. IJP. 2001;33:456-7.

10. Beg MA, Dutta S, Varma A, Kant R, Bawa S, Anjoom M, et al. Study on drug prescribing pattern in hypertensive patients in a tertiary care teaching hospital at Dehradun, Uttarakhand. Int J Med Sci Public Health. 2014;3:922-6.

11. Tiwari H, Kumar A, Kulkarni SK. Prescription monitoring of anti-hypertensive drug utilisation at the Punjab University Health Centre in India. Singapore Med J. 2004;45:117-20.

12. Pai PG, Shenoy J, Sanji N. Prescribing patterns of antihypertensive drugs in a South Indian tertiary care hospital. Drug Invention Today. 2011;3:38-40.

13. Etuk E, Isezuo SA, Chika A, AkucheJ, Ali M. Prescription pattern of anti-hypertensive drugs in a tertiary health institution in Nigeria. Ann Afr Med. 2008;7:128-32.

14. Sakthi S, Thomas S, Sivakumar KK, Karhikeyan J, Saravana kumar N. Assessment of anti hypertensive prescribing pattern and patient counseling in an urban population. Der Pharmacia Lettre. 2010;2:156-63.

15. Mancia G, Backer GD, Dominiczak A, Cifkova R, Fagard R, Germano G, et al. 2007 ESH-ESC practice guidelines for the management of arterial hypertension: ESH-ESC Task Force on the 
management of arterial hypertension. Eur Heart J. 2007;28:1462-536.

16. Seventh Report of the Joint National Committee on Prevention, Detection, Evaluation and Treatment of High Blood Pressure. 2003: 1-86.

17. Sandozi T, Emani VK. Survey of prescription pattern of anti-hypertensive drugs in hypertensives and hypertension associated diabetics. Int $\mathbf{J}$ Pharm Bio Sci. 2010;1:23-6.

18. Solanki KC, Mistry RA, Singh AP, Jadav SP, Patel NM, Trivedi HR. Drug utilization study of antihypertensive drugs and their adverse effects in patients of a tertiary care hospital. J Clin Exp Res. 2013;1:58-67.

19. Jhaj R, Goel NK, Gautam CS, Hota D, Sangeeta B, Sood A, et al. Prescribing patterns and cost of antihypertensive drugs in an internal medicine clinic. Indian Heart J. 2001;53:323-7.

20. Catic T, Begovic B. Outpatient antihypertensive drug utilization in Canton Sarajevo during ve years period (2004-2008) and adherence to treatment guidelines assessment. Bosn J Basic Med Sci. 2011;11:97-102.

21. Frattola A, Parati G, Cuspidi C, Albini F, Mancia G. Prognostic value of 24-hour blood pressure variability. J Hypertens. 1993;11:1133-7.
22. Bakris G. Are there effects of renin-angiotensin system antagonists beyond blood pressure control? Am J Cardiol. 2010;105:21-9.

23. Datta S. Utilization Study of Antihypertensives in a South Indian Tertiary Care Teaching Hospital and Adherence to Standard Treatment Guidelines. J Basic Clin Pharma. 2017;8:33-7.

24. Khurshid F, Aqil M, Alam MS, Kapur P, Pillai KK. Monitoring of adverse drug reactions associated with antihypertensive medicines at a university teaching hospital in New Delhi. Daru. 2012;20:34.

25. Akici A, Kalaca S, Ugurlu U, Hale Z. Toklu, Oktay S. Antihypertensive drug utilization at health centres in a district of Istanbul. Pharm World Sci. 2007;29:116-21

26. Quick JD, Hogerzeil HV, Velasquez G, Rago L. Twenty-five years of essential medicines. Bull World Health Organ. 2002;80:913-4.

Cite this article as: Khan S, Maiti RN, Mandal S. Pattern of use of anti-hypertensive drugs amongst hypertensive patients in a tertiary care hospital: a cross sectional, observational study. Int J Basic Clin Pharmacol 2020;9:89-95. 